\title{
Diversidade de peixes capturados em currais de pesca na praia de Moitas, Amontada, (Ceará, Brasil)
}

\author{
Diversity of fish caught in fishing pens at Moitas beach, \\ Amontada, (Ceará, Brazil)
}

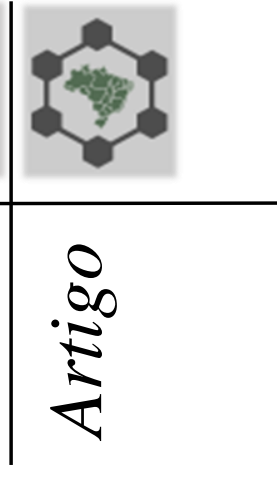

\section{Larissa Pinto da Costa ${ }^{1}$, Reynaldo Amorim Marinho ${ }^{2}$, Raimundo Nonato de Lima Conceição ${ }^{3}$ e Lilia Freire Freitas ${ }^{4}$}

Resumo: A pesca artesanal é caracterizada como uma atividade de pequena escala, que se utiliza de poucos instrumentos tecnológicos e geralmente praticada como forma de subsistência, gerando uma renda para o pescador e adicionando uma proteína de qualidade na sua alimentação. Os currais de pesca estão entre as artes de pesca utilizadas pelos pescadores artesanais por toda a costa brasileira. A costa do litoral do Ceará, Brasil, possui características adequadas para a instalação de currais de pesca, sendo muito utilizado por pescadores da região. Assim como em outras praias do litoral Oeste do Ceará, como nos municípios de Acaraú, Camocim e Paracuru, a praia de Moitas, no município de Amontada, também se utiliza dos currais de pesca para a captura de peixes. Devido à grande diversidade de espécies capturadas com essa arte de pesca, faz-se necessária a realização de estudos que possam auxiliar no seu ordenamento pesqueiro e manutenção de seus estoques, além de conhecer a diversidade dos recursos, os estoques capturáveis, entre outros. Diante o exposto, o presente trabalho teve como objetivo determinar a diversidade dos peixes capturados na pesca de curral, na praia de Moitas, Amontada, CE. Além de estimar a composição da amostra capturada que é susceptível a armadilha de pesca, verificar a variação da riqueza ao longo do período de estudo e avaliar a variação da diversidade e abundância das espécies no mesmo período. Os exemplares de peixes capturados nos currais da área de estudo foram coletados no período de abril a dezembro de 2020, em campanhas mensais, totalizando 9 campanhas, realizadas em horário estabelecido pelos pescadores, geralmente no período de maré vazante, de modo a não interferir na rotina de trabalho dos mesmos. Após a coleta, os exemplares foram identificados por meio de trabalhos e manuais para identificação de espécies marinhas, sendo identificados 1.087 indivíduos, distribuídos em 2 Classes, 4 Ordens, 14 famílias e 22 espécies. As espécies mais abundantes foram a Eugerres brasilianus, Selene vomer e Mugil incilis. Todos os índices ecológicos utilizados apontaram os currais de pesca da Praia de Moitas como áreas de média biodiversidade de peixes capturados, apresentando diversidade de Shannon-Wiener $\left(\mathrm{H}^{\prime}=2,10\right.$ nats/indivíduo), equitabilidade de Pielou $\left(\mathrm{J}^{\prime}=\right.$ $0,67)$ e riqueza de Margalef $(\mathrm{DMg}=3,00)$.

Palavras-chave: Pesca artesanal. Diversidade de espécies. Litoral Oeste do Ceará.

Abstract: Artisanal fishing is characterized as a small-scale activity, which uses few technological instruments and is generally practiced as a means of subsistence, generating an income for the fisherman and adding a quality protein to his diet. The fishing corrals are among the fishing techniques used by artisanal fishermen throughout the Brazilian coast. The coast of Ceará, Brazil, has adequate characteristics for the installation of fishing corrals, being widely used by fishermen in the region. As in other beaches on the west coast of Ceará, such as in the municipalities of Acaraú, Camocim and Paracuru, Moitas beach, in the municipality of Amontada, also uses fishing corrals to catch fish. Due 
to the great diversity of species caught with this fishing technique, it is necessary to carry out studies that can assist in its fishing order and maintenance of stocks, in addition to knowing the diversity of resources, the stocks that can be capture, among others. In view of the above, this study aims to determine the diversity of fish caught in fishing corrals, at Moitas beach, Amontada, CE. In addition to estimating the composition of the captured sample that is susceptible to fishing traps, verifying the variation in richness over the study period and evaluating the variation in diversity and abundance of species in the same period. The specimens of fish caught in the corrals of the study area were collected from April to December 2020, in monthly campaigns, totaling 9 campaigns, carried out at a time established by the fishermen, usually in the period of low tide, so as not to interfere in their work routine. After collection, the specimens were identified through works and manuals for the identification of marine species. 1,087 individuals were identified, distributed in 2 Classes, 4 Orders, 14 families and 22 species. The most abundant species were Eugerres brasilianus, Selene vomer and Mugil incilis. All the ecological indexes used indicated the fishing corrals of Moitas beach as areas of medium biodiversity of fish caught, presenting Shannon-Wiener diversity $\left(\mathrm{H}^{\prime}=2.10\right.$ nats / individual), Pielou equitability $(\mathrm{J} '=0,67)$ and Margalef's wealth $(\mathrm{DMg}=3.00)$.

Keywords: Artisanal fishing. Diversity of species. Ceara's West Coast.

\section{http://dx.doi.org/}

Autor para correspondência: Email: marinho.rey@gmail.com

Recebido em 10.03.2021 Aceito em 30.06.2021

${ }^{1}$ Engenheira de Pesca. Email: larissapinto.lp96@gmail.com

${ }^{2,3}$ Professor Doutor da Universidade Federal do Ceará. Emails: marinho.rey@gmail.com; nonatodelima@gmail.com;

4 Engenheira de Pesca. Doutoranda da Universidade Federal do Ceará. Email: lfreire406@gmail.com

\section{Introdução}

A pesca artesanal é caracterizada como uma atividade de pequena escala, que se utiliza de poucos instrumentos tecnológicos e geralmente praticada como forma de subsistência, gerando uma renda para o pescador $\mathrm{e}$ adicionando uma proteína de qualidade na sua alimentação. Ela é responsável por cerca de metade do pescado capturado mundialmente (FAO, 2017). Essa atividade é considerada como incerta pelos pescadores devido a sua imprevisibilidade, já que em um dia eles podem obter uma produção estimada para todo o mês, mas também podem não capturar o básico para atender as demandas familiares (FERNANDES, 2008).

Os currais são considerados armadilhas fixas, podendo ser construídos com cercas, telas, redes, entre outros materiais (TAVARES et $a l ., 2005)$. Estão entre as artes de pesca utilizadas pelos pescadores artesanais por toda a costa brasileira (MENDONÇA et al., 2011). A costa do litoral do Ceará, Brasil, possui características adequadas para a instalação de currais de pesca, sendo muito utilizado por pescadores da região (MASIH NETO et al., 2018). 
Assim como em outras praias do litoral Oeste do Ceará, os pescadores da praia de Moitas também se utilizam dos currais de pesca para a captura do pescado. Os currais são considerados uma arte pesca pouco seletiva, resultando na captura de uma grande diversidade de espécies de peixes, podendo ser de interesse comercial ou não (DIAS, 2019).

Por não oferecerem nenhum tipo de atrativo para a captura do pescado, os currais muitas vezes se localizam próximos a costa e são dependentes da ação das marés (TAVARES et al., 2005). Nas marés altas os peixes entram na armadilha e quando a maré baixa os mesmos ficam presos no interior, e nesse momento os pescadores os capturam com uma rede auxiliar e os transportam em pequenas embarcações para pontos de comercialização em terra (MASIH NETO et al., 2018).

Os índices ecológicos são muito utilizados por reunirem informações sobre vários aspectos de uma comunidade e expressá-los em forma de números, refletindo a situação da comunidade (FLORES-LOPES; CETRA; MALABARBA, 2010). Devido à grande diversidade de espécies capturadas com essa arte de pesca, faz-se necessário a realização de estudos que possam auxiliar no seu ordenamento pesqueiro e manutenção de seus estoques, além de conhecer a diversidade dos recursos, os estoques capturáveis, entre outros.

O presente trabalho teve como objetivo determinar a diversidade dos peixes capturados na pesca de curral, na praia de Moitas, Amontada, CE. Além de estimar a composição da amostra capturada que é susceptível a armadilha de pesca, verificar a variação da riqueza ao longo do período de estudo e avaliar a variação da diversidade e abundância das espécies no mesmo período.

\section{Material e métodos}

Os exemplares de peixes capturados nos currais da área de estudo foram coletados no período de abril a dezembro de 2020, em campanhas mensais, totalizando 9 campanhas. A praia escolhida foi a do Distrito de Moitas, no município de Amontada, que se localiza no litoral Oeste do Ceará. As coletas foram realizadas em horário estabelecido pelos pescadores, geralmente no período de maré vazante, de modo a não interferir na rotina de trabalho dos mesmos.

Os currais de pesca foram escolhidos como método de coleta devido a sua importância social e econômica para a comunidade local, além de serem armadilhas fixas, facilitando no momento da coleta. Os 
currais utilizados na região são do tipo furtado, sendo divido em espia, sala, chiqueiro e chiqueirinho (Figura 1). As espias servem para guiar os animais para a sala do curral, a sala é o primeiro compartimento no qual ocorre a primeira fase do aprisionamento, o chiqueiro é o segundo compartimento, de menor área em relação a sala, dificultando ainda mais a saída dos animais, e o chiqueiro de matar é o terceiro compartimento, que tem a mesma finalidade do chiqueiro em relação a sala, mas também é o local da despesca (LUCENA et al., 2013). O fundo do chiqueiro de matar é cimentado para impedir que os animais se escondam e evitem ser capturados.

Figura 1. Esboço gráfico do curral tipo furtado, e suas repartições: espia (A), sala (B), chiqueiro (C) e chiqueiro de matar (D).

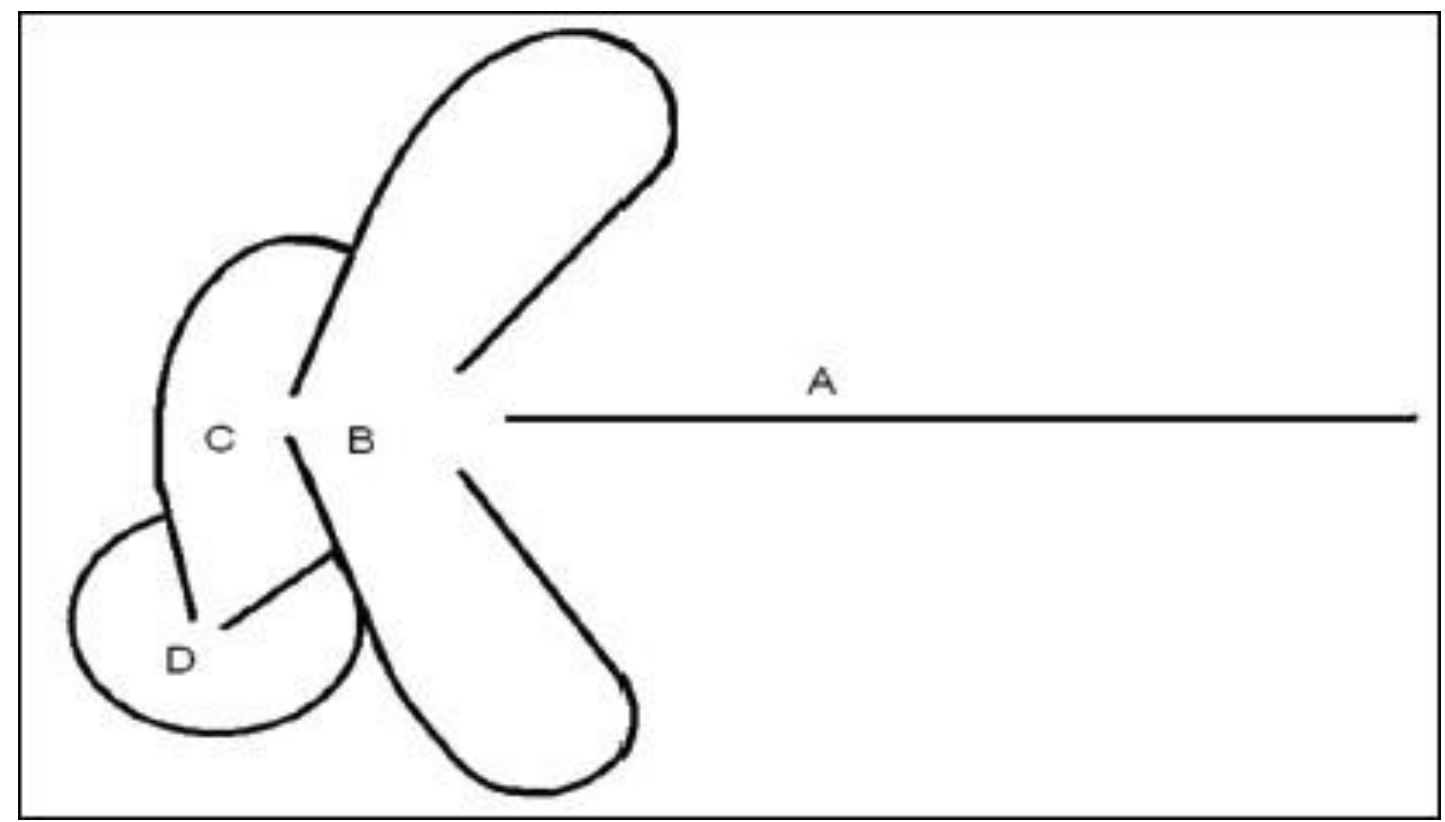

Fonte: LUCENA et al., 2013.

O material utilizado na construção dos currais são: os mourões de madeira, as cintas paras travar os mourões uns aos outros, e as varas para manter as telas em pé. As telas podem ser feitas com linhas de pesca (ou cabos trançados de 1 a 7 milímetros) ou arames galvanizados, que podem precisar de reposição a partir do terceiro mês de uso, devido a avarias causadas pelo movimento das marés ou pela oxidação do material A abertura de malhas das telas é entre 7 e 10 centímetros. Apenas os mourões não 
precisam ser substituídos, podendo ser utilizados por vários anos.

Para realização da manutenção e despesca dos currais são precisos de duas a três pessoas, os vaqueiros. Enquanto uma delas se ocupa em confeccionar as telas para substituição, as outras duas ficam responsáveis pelas despescas, que ocorrem duas vezes ao dia, na maré baixa.

Como os currais se localizam bem próximos a costa, não é utilizado nenhum tipo de embarcação para chegar até os mesmos.

Geralmente as pessoas envolvidas fazem parte da mesma família e a produção é utilizada para alimentar a família, sendo o excedente de captura comercializado.
Após a coleta, os exemplares foram identificados por meio de trabalhos e manuais para identificação de espécies marinhas, como os realizados por Figueiredo (1977), Menezes e Figueiredo (1980), Lessa e Nóbrega (2000), Menezes et al., (2003), Nobrega et al., 2009) e Ceará (2005), além do site FISHBASE disponível no endereço (www.fishbase.com).

A caracterização da diversidade e abundância foi obtida pelo índice de Shannon- Wiener ( $\left.\mathrm{H}^{\prime}\right)$ e pelo índice de uniformidade de Pielou (J') baseados na abundância proporcional das espécies, sugeridos por ODUM E BARRETT (2007). O índice de Shannon-Wiener (H') leva em conta a uniformidade das abundâncias das espécies e baseia-se na seguinte equação:

$$
\mathrm{H}^{\prime}=-\sum_{i=1}^{\mathrm{S}}\left(\mathrm{p}_{i} \cdot \ln \mathrm{p}_{i}\right),
$$

onde:

$\mathrm{H}^{\prime}=$ valor médio do grau de incerteza em nats/individuo;

$\mathrm{S}=$ número total de espécies presentes na amostra;

$\mathrm{p} i=$ participação relativa da espécie $i$, em que:

n $i=$ número de indivíduos pertencentes a $i$-ésima espécie da amostra;

$\mathrm{N}=$ número de indivíduos da amostra.

A partir das observações feitas por Magurran (2019), a seguinte classificação de diversidade foi adotada:

- $\quad H^{\prime}<1$ nats/indivíduo = muito baixa;

- $\quad 1>\mathrm{H}^{\prime}<2$ nats/indivíduo = baixa; 
- $\quad 2>\mathrm{H}^{\prime}<3$ nats/indivíduo = média;

- $\quad 3>\mathrm{H}^{\prime}<4$ nats/indivíduo = alta;

- $\quad H^{\prime}>4$ nats/indivíduo = muito alta

O índice de Pielou ( $\left.\mathrm{J}^{\prime}\right)$ é calculado com base na razão entre a diversidade observada e a diversidade máxima, indicando a distribuição da abundância entre as espécies:

J'= H' / H'máx

onde:

$\mathrm{J}^{\prime}=$ equitabilidade;

$\mathrm{H}^{\prime}=$ diversidade;

H'máx = Ln S = diversidade máxima;

$\mathrm{S}=$ número total de espécies presentes na amostra.

Pelo número de espécies 2006), e por isso, a riqueza foi calculada geralmente depender da quantidade de pela riqueza de Margalef (d), que diz amostras que são feitas, o parâmetro $S$ respeito ao número de espécies não reflete a riqueza de uma presentes na amostra, usando a seguinte comunidade (TOWNSEND et al., equação (MARGALEF, 1957):

$\mathrm{d}=(\mathrm{S}-1) / \ln \mathrm{N}$

onde:

$\mathrm{d}=$ riqueza;

$\mathrm{S}=$ número total de espécies presentes na amostra; e

$\mathrm{N}=$ número de indivíduos da amostra.

Todos os cálculos utilizados média de 121 indivíduos coletados por nessas análises foram feitos com 0 campanha. Os meses que apresentaram auxílio do programa estatístico BioEstat maior número de espécimes amostrados 5.3 .

\section{Resultados e discussão} foram abril, maio e junho, com 197, 171

Durante o período amostral de e 201 indivíduos, respectivamente. Giannini e Paiva Filho (1995) e Santana abril a dezembro de 2020 foram e Severi (2009) encontraram maiores coletados 1.087 indivíduos, com uma abundâncias em seus estudos no período 
chuvoso.

Os animais coletados foram identificados e distribuídos em 2 Classes, 4 Ordens, 14 famílias e 22 espécies. Sendo a grande maioria de peixes ósseos e apresentando apenas uma espécie da classe dos Chondrichthyes (tubarões e raias), Aetobatus narinari, conforme a classificação sistemática proposta por MENEZES et al., 2003.

A classe Actinopterygii apresentou 4 Ordens, 13 familias e 21 espécies. De forma geral, a classe foi dominada pela Ordem Perciformes $(63,66 \%)$, seguida por Mugiliformes (29,62\%), Clupeiformes $(6,44 \%)$ e Elopiformes (0,18\%). Uma maior concentração de indivíduos da Ordem Perciformes também foi encontrada Masih Neto et al., (2018) no litoral cearense e por Castro (1997) em estudo na Ilha de São Luís (MA).

As espécies Eugerres brasilianus, da família Gerreidae, Selene vomer, da família Carangidae, Genyatramus luteus, da família Haemulidae e Lopholatilus villari, da família Malacanthidae foram as mais representativas da Ordem Perciformes, com $27,14 \% ; 21,34 \% ; 3,96 \% ; 3,50 \%$, respectivamente.

A Ordem Mugiliformes apresentou três espécies da família Mugilidae, Mugil incilis (20,15\%), Mugil curema (9,01\%) e Mugil liza $(0,46 \%)$. Os Clupeiformes apresentaram duas espécies, a Opisthonema oglinum (5,61\%), da família Clupeidae e a Anchovia clupeoides (0,83\%), da família Eugralidae. A Ordem Elopiformes apresentou apenas uma espécie, a Megalops atlanticus $(0,18 \%)$, da família Megalopidae.

Das 14 famílias encontradas, 5 delas corresponderam a $91,90 \%$ do total coletado, sendo elas, as famílias Mugilidae (29,62\%), Gerreidae (27,14\%), Carangidae (23,37\%), Haemulidae $(6,16 \%)$ e Clupeidae $(5,61 \%)$. As outras 9 famílias corresponderam a $8,10 \%$.

Do total de espécies identificadas, três contribuíram com $68,63 \%$ do total capturado, Eugerres brasilianus $(27,14 \%)$, Selene vomer $(21,34 \%)$ e Mugil incilis (20,15\%) (Tabela 1). 
Tabela 1. Abundância e frequência relativa (FR) das espécies capturadas em currais de pesca, na Praia de Moitas, Amontada, Ceará, no período de abril a dezembro de 2020.

\begin{tabular}{|c|c|c|c|c|c|c|c|c|c|c|c|}
\hline \multirow[b]{2}{*}{ ESPÉCIE } & \multicolumn{9}{|c|}{ CAMPANHAS } & \multirow[b]{2}{*}{ TOTAL } & \multirow{2}{*}{$\begin{array}{c}\text { FR } \\
(\%)\end{array}$} \\
\hline & ABR & MAI & JUN & JUL & AGO & SET & OUT & NOV & DEZ & & \\
\hline E. brasilianus & 40 & 5 & 110 & 39 & 25 & 55 & 15 & - & 6 & 295 & 27,138 \\
\hline S. vômer & 72 & 90 & - & - & 4 & - & 43 & 23 & - & 232 & 21,343 \\
\hline M. incilis & - & - & 30 & 40 & 20 & 30 & 48 & 36 & 15 & 219 & 20,147 \\
\hline M. curema & 57 & 11 & 30 & - & - & - & - & - & - & 98 & 9,015 \\
\hline O. oglinum & - & 51 & - & - & - & - & 10 & - & - & 61 & 5,611 \\
\hline G. luteus & 2 & 5 & 20 & - & 16 & - & - & - & - & 43 & 3,955 \\
\hline L. villarii & - & - & - & - & - & - & 20 & - & 18 & 38 & 3,495 \\
\hline A. virginicus & - & - & - & - & 5 & - & - & 18 & - & 23 & 2,115 \\
\hline C. undecimalis & - & - & 5 & 1 & 1 & 5 & 1 & - & - & 13 & 1,195 \\
\hline O. saliens & 12 & - & - & - & - & - & - & - & - & 12 & 1,103 \\
\hline P. arenatos & - & - & - & - & - & - & - & 10 & - & 10 & 0,919 \\
\hline A. clupeoides & - & 3 & 1 & 5 & - & - & - & - & - & 9 & 0,827 \\
\hline C. hippos & - & 1 & - & 2 & 2 & - & - & - & - & 5 & 0,459 \\
\hline M. liza & - & - & 5 & - & - & - & - & - & - & 5 & 0,459 \\
\hline C. chrysurus & 1 & 2 & - & - & - & - & - & - & - & 3 & 0,275 \\
\hline L. surinamensis & 1 & - & - & - & - & 1 & - & - & 1 & 3 & 0,275 \\
\hline C. crysos & - & 2 & - & - & - & - & - & - & - & 2 & 0,183 \\
\hline M. atlanticus & - & - & - & - & 1 & - & - & 1 & - & 2 & 0,183 \\
\hline S. brasiliensis & 1 & - & - & - & - & - & - & - & - & 1 & 0,091 \\
\hline H. parra & - & - & - & - & - & - & 1 & - & - & 1 & 0,091 \\
\hline A. narinari & - & 1 & - & - & - & - & - & - & - & 1 & 0,091 \\
\hline TOTAL & 197 & 171 & 201 & 87 & 74 & 91 & 138 & 88 & 40 & 1087 & 100 \\
\hline
\end{tabular}

Fonte: Elaborado pela autora.

Tremain e Adams (1995) associaram a variação de abundância a mudanças nos fatores bióticos do local de estudo, ao longo do período amostral.

Os meses que apresentaram menor número de espécimes foram julho, agosto e setembro, com 87, 74 e 40 animais, respectivamente. A baixa abundância de indivíduos coletados também pode ser consequência da proximidade dos currais de pesca a faixa de praia, já que os mesmos se localizam na zona entre marés.

Houve uma semelhança entre as famílias e espécies mais capturadas com o estudo realizado por Dias (2019). No entanto, as diferenças podem ser explicadas devido a maior duração do período amostral do trabalho supracitado, que foi de quatro anos, enquanto $o$ presente trabalho teve duração de nove meses, possibilitando a captura de uma maior diversidade de 
espécies. Essa dominância de um pequeno número de espécies também foi observada nos estudos de HOLANDA (2009), DIAS (2019), FÉLIX et al. (2006) e MATIAS (1994).

\section{Índices ecológicos}

A variação do índice de diversidade Shannon-Wiener $\left(\mathrm{H}^{\prime}\right)$ calculada para a pesca de curral pode ser encontrado no Gráfico 1 Os maiores índices de diversidade foram registrados nos meses de abril ( $\mathrm{H}^{\prime}=1,50$ nats/indivíduo), agosto $\left(\mathrm{H}^{\prime}=1,60\right.$ nats/indivíduo) e outubro $\left(\mathrm{H}^{\prime}=1,51\right.$ nats/indivíduo). Apesar de apresentarem os maiores índices, esses meses são considerados como de baixa diversidade. $\mathrm{O}$ mês que apresentou menor índice de diversidade foi setembro $\left(H^{\prime}=0,88\right.$ nats/indivíduo), sendo o único mês classificado como de diversidade muito baixa, de acordo com a classificação de MAGURRAN (2019).

Considerando as coletas realizadas em todo o período amostral, o índice de diversidade calculado foi de $\mathrm{H}^{\prime}=2,10$ nats/indivíduo, sendo classificado como um ambiente de média diversidade, segundo MAGURRAN (2019).

Segundo Margalef (1974), o índice de diversidade Shannon-Wiener $\left(H^{\prime}\right)$ é geralmente de 0,69 a 2,43 nats/indivíduo para populações de peixes, sendo o índice encontrado nesse estudo pertencente a esse intervalo.

$\mathrm{O} \mathrm{H}^{\prime}$ máximo calculado para a situação foi de 3,10 nats/indivíduo, o que faria o ambiente ser considerado de alta diversidade. Esse valor poderia ter sido alcançado se o período amostral se prolongasse, já que o número de espécies depende do número de amostras (TOWNSEND et al., 2006).

Carvalho e Araújo (2000), calcularam um valor de diversidade de 2,22 nats/indivíduo em pesquisa na zona entre marés na Praia do Pecém (CE), valor semelhante ao encontrado no presente trabalho, devido aos currais de pesca se encontrarem na mesma zona de influência das marés.

E em pesquisa com currais de pesca no litoral de Acaraú (CE), Masih Neto et al., (2018), encontraram um valor de 3,3 nats/individuo, sendo o local classificado como de alta diversidade.

Uma das possíveis causas dessa diferença de valores pode ser a maior distância dos currais em relação a costa, que no estudo de Acaraú ficavam entre 1,7 a 3,2 km de distância. 
Gráfico 1 Variação do Índice de diversidade de Shannon-Wiener ( H') calculado para o pescado capturado nos currais de pesca da Praia de Moitas, Amontada, CE, no período de abril a dezembro de 2020.

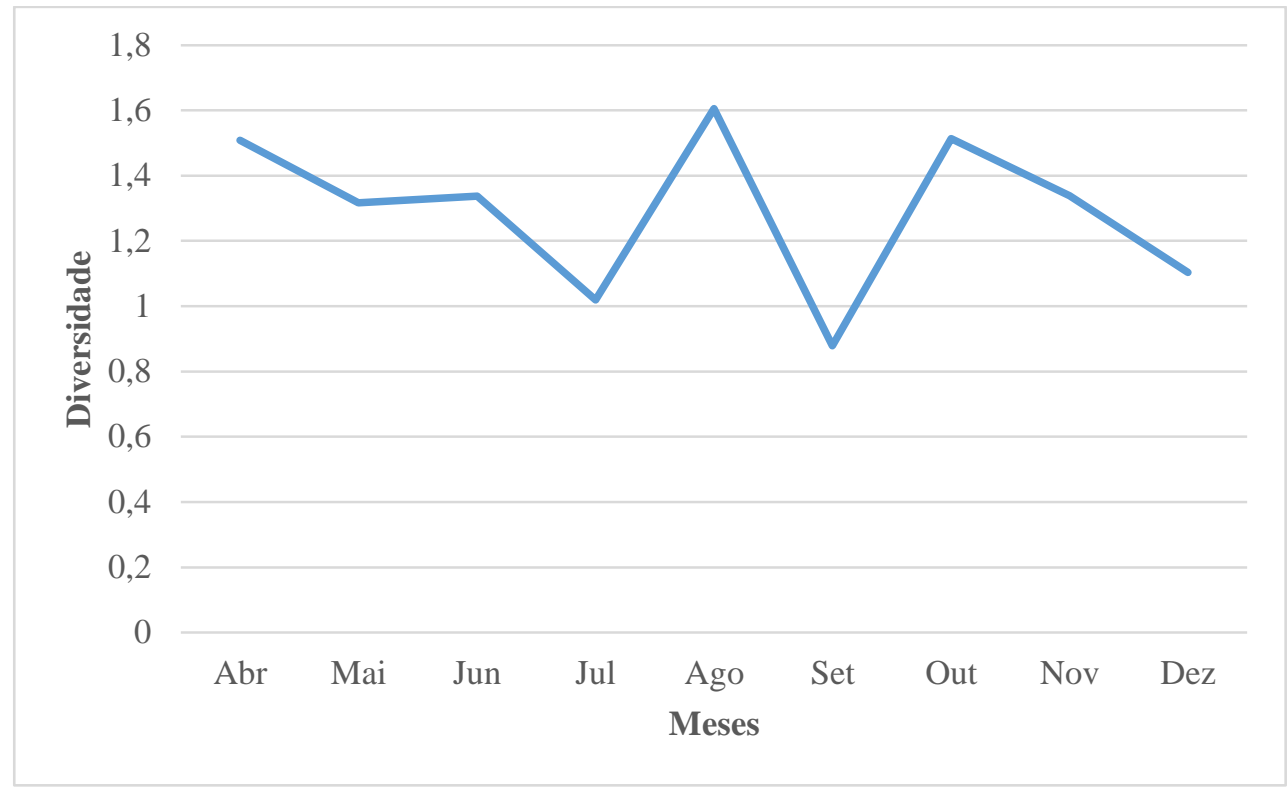

Fonte: Elaborado pela autora.

Sobre a variação da Carvalho e Araújo (2000) e Félix et al., equitabilidade ou uniformidade de (2006) em seus estudos.

Pielou (J') calculada para os dados Com relação à variação do obtidos com os currais de pesca da Praia de Moitas (CE), os meses de maior uniformidade foram outubro $\left(\mathrm{J}^{\prime}=0,77\right)$, novembro $\left(\mathrm{J}^{\prime}=0,83\right)$ e dezembro $\left(\mathrm{J}^{\prime}=\right.$ 0,79). E os meses de menor uniformidade foram maio $\left(\mathrm{J}^{\prime}=0,57\right)$, julho $\left(\mathrm{J}^{\prime}=0,63\right)$ e setembro $\left(\mathrm{J}^{\prime}=0,63\right)$. Para todo o período amostral, a equitabilidade de Pielou (J') calculada foi 0,67 , sendo considerada uma uniformidade significativa entre as espécies de peixes encontradas, de acordo com Odum (2010). Valores semelhantes foram encontrados por índice de riqueza para o período de coleta pode-se constatar que os meses com os maiores índices de riqueza foram abril $(\mathrm{DMg}=1,51)$, maio $(\mathrm{DMg}$ $=1,75)$ e agosto $(\mathrm{DMg}=1,62)$, sendo semelhante ao encontrado por Dias (2019) em um estudo com currais de pesca em Pernambuco. Os menores índices de riqueza foram encontrados nos meses de setembro $(\mathrm{DMg}=0,66) \mathrm{e}$ dezembro ( $\mathrm{DMg}=0,81)$. Em geral, as campanhas apresentaram um baixo índice de riqueza, mas quando observado o valor calculado para todo o 
estudo $(\mathrm{DMg}=3,00)$, a comunidade de peixes amostrada pode ser considerada de média riqueza. Como exposto por Margalef (1957), valores abaixo de 2,0 são apontados como baixa biodiversidade e valores superiores a 5,0 são considerados indicadores de alta biodiversidade.

Castro (1997) ressaltou que as estimativas de abundância e riqueza de espécies podem ser tendenciosas, pois dependem do tipo de arte de pesca utilizado na captura dos animais e no período de amostragem e horários em que ocorreram. Há ainda, a interferência de fatores bióticos (como a predação e competição) e abióticos (hidrológicos, climatológicos), que podem influenciar na estrutura da comunidade do local de estudo.

\section{Conclusões}

Os currais de pesca da praia de Moitas, Amontada, Ceará, representam significativo aparelho de pesca artesanal na região. A maior abundância de capturas foi constatada nos meses correspondentes ao período chuvoso. No entanto, a comprovação desta hipótese carece de estudos mais detalhados para que possa ser avaliada a influência da pluviosidade nas capturas de pescado na área pesquisada.

As espécies que apresentaram maior frequência relativa são também as que mais ocorrem em outros locais da região. Foram identificados como mais representativas Eugerres brasilianus $(27,14 \%)$, Selene vomer $(21,34 \%)$ e Mugil incilis (20,15\%), somando $68,63 \%$ do total capturado.

Os resultados apontaram que, conforme os índices ecológicos estudados, os currais de pesca da Praia de Moitas se identificam como áreas de média biodiversidade de peixes capturados, de acordo com os dados apresentados de diversidade de Shannon-Wiener, equitabilidade de Pielou e riqueza de Margalef.

\section{Referências Bibliográficas}

BRASIL. Empresa Brasileira de Pesquisa Agropecuária. Boletim de Pesquisa e Desenvolvimento 3: Pesca artesanal brasileira. Aspectos conceituais, históricos, institucionais e prospectivos. 2014. Disponível em: https://ainfo.cnptia.embrapa.br/digital/bi tstream/item/pdf. Acesso em: 25 jan. 2021.

CARVALHO, R.A.A.; ARAÚJO, M.A. Ictiofauna recifal da região entre-marés da praia do Pecém, Ceará, Brasil. Monografia de graduação em Engenharia de Pesca da Universidade Federal do Ceará, Fortaleza, 32 pp. 2000.

CASTRO, A.C.L. Características ecológicas da ictiofauna da Ilha de São Luís-MA. Boletim do Laboratório de Hidrobiologia, v. 10, n. 1. P. 1:18. 1997.

CEARÁ -Zoneamento Ecológico e Econômico da Zona Costeira do Estado do Ceará: ictiofauna dos estuários do 
estado do Ceará. Fortaleza, Governo do Estado do Ceará: UFC/SEMACE/LABOMAR, 2005.

DIAS, V.S. Composição e variação temporal da assembleia de peixes capturados em currais no litoral norte do estado de Pernambuco. 2019. Monografia de graduação em Engenharia de Pesca na Universidade Federal Rural de Pernambuco, Recife, 29 f. 2019.

FAO - Organização das Nações Unidas para a Alimentação e Agricultura. Diretrizes Voluntárias para Garantir a Pesca de Pequena Escala Sustentável no Contexto da Segurança Alimentar e da Erradicação da Pobreza. $2017 . \quad$ Disponível em: http://www.fao.org/3/i4356pt/I4356PT. pdf. Acesso em: 24 jan. 2021.

FÉLIX, F.C.; SPACH, H.L.; HACKRADT, C.W.; MORO, P.S.; ROCHA, D. C. Abundância sazonal e a composição da assembleia de peixes em duas praias estuarinas da Baía de Paranaguá, Paraná. Revista Brasileira de Zoociências, v. 8, n. 1, p. 35:47. 2006.

FERNANDES, G.F. Caracterização da pesca artesanal no distrito de Bitupitá, município de Barroquinha. Monografia de Graduação em Engenharia de Pesca na Universidade Federal do Ceará. 38 f. 2008.

FIGUEIREDO, J.L. Manual de Peixes Marinhos do Sudeste do Brasil: Volume I: Cações, raias e quimeras. São Paulo: Museu de Zoologia/USP, 111 pp. 1997.

FLORES-LOPES, F.; CETRA， M.; MALABARBA, L.R. Utilização de índices ecológicos em assembleias de peixes como instrumento de avaliação da degradação ambiental em programas de monitoramento. Biota Neotropica, v. 10, n. 4, p. 183-193. 2010.
GIANNINI, R.; PAIVA FILHO, A.M. Análise comparativa da ictiofauna da zona de arrebentação de praias arenosas do Estado de São Paulo, Brasil. Boletim do Instituto Oceanográfico, v. 43, n. 2, p. 141-152. 1995.

HOLANDA, J.S. Caracterização da comunidade de peixes demersais na área de influência do sistema de disposição oceânica dos esgotos sanitários de Fortaleza (SDOES). $45 \mathrm{f}$. Monografia de Especialização em Engenharia de Pesca. Universidade Federal do Ceará, Fortaleza, 2009.

LESSA, R.; NÓBREGA, M.F. Guia de identificação de peixes marinhos da Região Nordeste. Programa REVIZEE, Score-NE. Recife, PE, Brasil, 128 pp. 2000.

LUCENA, F.P.; CABRAL, E.; SANTOS, M.C.F.; OLIVEIRA, V.S.; BEZERRA, T.R.Q. A pesca de currais para peixes no litoral de Pernambuco. Bol. Téc. Cient. CEPENE, Tamandaré - PE - v. 19, n. 1, p. 93-102, 2013.

MAGURRAN, A.E. Medindo a diversidade biológica. Curitiba: Editora da Universidade Federal do Paraná, 260 pp. 2019.

MARGALEF, R. Ecología. Barcelona: Ediciones Omega S.A., 951 pp. 1974.

MARGALEF, R. La teoria de la información en Ecología. Memorias de la Real Academia de Ciéncias y Artes de Barcelona, v. 32, n. 13, p. 373-436. 1957.

MASIH NETO, T.; SALLES, R.; SANTOS, E.S.; SOUSA NETO, M.A.; MAIA, L.P. Biodiversidade da Ictiofauna nos currais de pesca no litoral de Acaraú, Ceará, Brasil. Arquivo de Ciências do Mar, Fortaleza, v. 50, n. 2, p.18-29. 2018. 
MATIAS, J.F.N. Estudo da diversidade das espécies capturadas por currais de pesca na praia de Almofala-Ce, durante os anos de 1990, 1991 e 1992. 1994. Monografia de Especialização em Engenharia de Pesca na Universidade Federal do Ceará, Fortaleza. 38 f. 1994.

MENDONÇA, J.T.; MACHADO, I.C.; JENSEN, L.V.; CAMPOLIMI, M.B.; LUCENA, A.; CARDOSO, T.A. Ordenamento da pesca com cercosfixos no estuário de Cananéia-IguapeIlha Comprida. Arquivo de Ciências do Mar, Fortaleza, v. 44, n. 2, p.36-51, 2011.

MENEZES, N. A.; FIGUEIREDO, J. L. Manual de peixes marinhos do sudeste do Brasil: Volume IV (Teleostei 3). São Paulo: Museu de Zoologia/USP, 48 pp. 1980.

MENEZES, N.A.; BUCKUP, P. A.; FIGUEIREDO, J.L.; MOURAET, R. L. (Ed.). Catálogo das espécies de peixes marinhos do Brasil. São Paulo: Museu de Zoologia da Universidade de São Paulo, 164 pp. 2003.

NOBREGA, M.F.; LESSA, R.; SANTANA, F.M. Peixes marinhos da região nordeste do Brasil. Fortaleza: Editora Martins \& Cordeiro. (Programa REVIZEE - Score Nordeste). 206 pp. 2009.
ODUM, E.P. Ecologia. 2. Ed. Rio de Janeiro: Guanabara Koogan S.A. 434 pp. 2010.

ODUM, E.P.; BARRETT, G.W. Fundamentos de Ecologia. 5. ed. São Paulo: Cengage Learning, 612 pp. 2007.

SANTANA, F.M. da S.; SEVERI, W. Composição e estrutura da assembleia de peixes da zona de arrebentação da praia de Jaguaribe, Itamaracá (PE). Bioikos, n. 23, v. 1, p. 3-17. 2009.

TAVARES, M.C. da S.; JÚNIOR, I. F.; SOUZA, R.A.L. de; BRITO, C. S. F. de. A pesca de curral no Estado do Pará.

Boletim Técnico-Científico do CEPNOR, Belém, PA, n. 5 p. 115-139. 2005.

TOWNSEND, C.R.; BEGON, M.; HARPER, J.L. Fundamentos em ecologia. 2. ed. Porto Alegre: Artmed, 2006. 592 pp.

TREMAIN, D.M.; ADAMS, D.H. Seasonal variations in species diversity, abundance, and composition of fish communities in the northern Indian River Lagoon, Florida. Bulletin of Marine Science, v. 57, n. 1, p. 171-192, 1995. 